\title{
O crescimento da liberdade como fim educacional: a relação entre o pensamento reflexivo e a liberdade na obra de John Dewey
}

Rômulo Ferreira Correa

José Claudio Matos

\section{Resumo}

Propõe analisar a relação entre o cultivo do pensamento reflexivo e o crescimento da liberdade individual, tendo como fonte principal a obra Como Pensamos (1933), de John Dewey. Para ele, a finalidade da educação é formar indivíduos livres, capazes de direcionar sua conduta e adaptar as condições do ambiente a seu favor. Nesse caso, o crescimento da liberdade é um efeito da educação que estimula o indivíduo ao exercício contínuo do pensamento reflexivo. O presente discurso procura mostrar por que o conceito evolutivo de liberdade de Dewey é mais eficiente do que a teoria educacional criticada por ele, que confunde liberdade com espontaneidade e, por causa disso, considera a criança livre para dirigir suas atividades. Essa confusão resulta na condenação da autoridade do professor e na perigosa ideia de que o ser humano imaturo não precisa de direção externa para alcançar a liberdade.

Palavras-chave: Dewey; liberdade; pensamento reflexivo; educação. 


\section{Abstract \\ The growth of freedom as an educational end: the relation between reflective thinking and freedom in John Dewey's work}

This article analyzes the relation between the cultivation of reflective thinking and the growth of individual freedom, based mainly on John Dewey's work "How we think" (1933). For Dewey, the end of education is to form free individuals, capable of directing their own conduct and of adapting environmental conditions to their benefit. In this case, the growth of freedom is an effect of education that stimulates the individual to the continuous exercise of reflective thinking. The present discourse intends to show the reason why Dewey's evolutionary concept of freedom is more efficient than the educational theory criticized by him, which confuses freedom with spontaneity, and for this reason, considers the child free to direct his/her activities. This confusion results in the condemnation of the teacher's authority and in the dangerous idea that immature human beings do not need external direction to achieve freedom.

Keywords: Dewey; freedom; reflective thinking; education.

\section{Introdução}

Teorias educacionais fundadas em um ideal de liberdade que contesta a autoridade do professor na direção das atividades do estudante têm exercido forte influência nos debates atuais sobre educação. Por isso, torna-se pertinente a obra do filósofo norte-americano John Dewey (1859-1952) - cuja produção é reconhecida no Brasil principalmente por suas ideias educacionais -, que apresenta como alternativa à concepção acima mencionada um conceito de liberdade baseado na teoria evolutiva. Contrapondo-se à compreensão de que liberdade significa apenas a ausência de obstáculos, para o autor, a liberdade é algo que se conquista vencendo obstáculos. É um equívoco supor que o ser humano nasce livre e tudo o que necessita para manifestar sua liberdade é que não o perturbem em seu caminho. Segundo Dewey, a liberdade pode vir a ser um atributo no futuro, se a educação do indivíduo tiver sido guiada por alguém mais experiente com o intuito de lhe formar hábitos de pensamento reflexivo. Nesse sentido, defende-se aqui que a liberdade apresentada por John Dewey exerce melhor a função de tornar mais livre a vida humana do que a concepção propagada pelas atuais versões pedagógicas do laissez-faire.

Para justificar essa posição, a este trabalho cumpre, primeiramente, esclarecer de que maneira a singularidade da noção deweyana de liberdade se deve à originalidade do método adotado pelo filósofo na 
investigação do assunto. Em seguida, é preciso identificar o conceito de liberdade existente na obra Como Pensamos ${ }^{1}$, de John Dewey, com as considerações que o autor faz sobre a relação entre o exercício do pensamento reflexivo e sua consequente influência no crescimento da liberdade individual. Considerando isso, será examinada a razão por que a finalidade da educação deve ser o crescimento da liberdade e de que maneira o autor avalia se esta finalidade é ou não benéfica à humanidade. Por fim, rematando a discussão, pretende-se evidenciar a carência de fundamentação científica das teorias educacionais que serão aqui chamadas de não-diretivas, em contraste com a teoria de Dewey fundamentada na teoria evolutiva -, que afirma que o desenvolvimento da liberdade ocorre por intermédio do cultivo da reflexão, pois somente dessa maneira pode crescer nos indivíduos a capacidade de estabelecer a própria direção.

\section{O problema da liberdade}

Observada a importância da experiência e do método científico na investigação filosófica de John Dewey, a forma assumida pelo problema da liberdade se manifesta por meio da seguinte questão: Filosofar acerca da liberdade contribui para tornar o indivíduo mais livre? Convém aqui ressaltar que as discussões teóricas que não apresentam efeito ou influência na vida prática são alvo de crítica por parte do autor, sendo denunciadas por sua inaplicabilidade e pelo prejuízo que suas conclusões não verificadas infligem à investigação. Servem de exemplo os arrazoados filosóficos que discorrem sobre a ideia de liberdade sem levar em conta o indivíduo em suas determinações físicas e sociais, de modo que conduzem o raciocínio por um caminho isolado da experiência, reduzindo, normalmente, o problema a uma formulação dualista e abstrata: o ser humano é ou não é livre? Possui

${ }^{1}$ Tendo em vista a intenção deste trabalho, a versão revisada de 1933, por conter adaptações com propósitos didáticos e acréscimos referentes à educação, apresenta-se mais oportuna que a original publicada em 1910. A definição de liberdade existente na obra, com base na qual este trabalho projeta o seu caminho, permanece a mesma nas duas edições, favorecendo assim a escolha daquela que aduz ao lado das reflexões sobre as formas de pensar suas respectivas consequências educacionais.

${ }^{2}$ Logo no início da obra Como Pensamos, Dewey qualifica o pensamento reflexivo como a melhor maneira de pensar, isto é, como a operação mental mais eficiente, que executa melhor o trabalho de que é capaz (Dewey, 1933, p.13). ou não liberdade?

Em oposição a essa espécie de raciocínio, a Dewey importa apenas a maneira de pensar que melhor influa nas condições objetivas da experiência: o pensamento reflexivo. ${ }^{2}$ Por isso, veremos que a liberdade na filosofia de Dewey é abordada de maneira distinta da tradicional. Resta saber, todavia, se a noção deweyana de liberdade faz diferença na prática, ou seja, se influi e modifica a experiência de maneira mais eficiente do que outras teorias. O problema da liberdade, tendo em vista a intenção deste estudo, assume portanto a seguinte hipótese: A concepção emergente da liberdade que, segundo Dewey, cresce em virtude do exercício do pensamento reflexivo é mais eficiente, isto é, funciona melhor que outras teorias que promovem a liberdade como valor educativo.

A hipótese de trabalho e as proposições que dela sucedem foram avaliadas por meio da análise textual das fontes teóricas, que serão mencionadas convenientemente no decurso deste artigo. O método 
consistiu no estudo da produção intelectual de John Dewey e de fontes bibliográficas secundárias. Processo que compreendeu, em primeiro lugar, a interpretação e análise da produção deweyana que faz referência à liberdade, tendo como fonte principal o livro Como Pensamos, e, em segundo lugar, a comparação e revisão crítica de comentadores e especialistas que procuram esclarecer e atualizar a obra do filósofo à luz de discussões científicas recentes. A aplicação desse método resultou na produção do presente discurso, que avalia e problematiza o pensamento de Dewey acerca da relação necessária entre a liberdade e o exercício do pensamento reflexivo. Pretende-se, dessa maneira, dar conta de questões filosóficas a respeito da liberdade que têm sido formuladas e discutidas no contexto atual do debate sobre educação.

Esclarecida a metodologia deste estudo, convém deter-se um pouco sobre a metodologia utilizada por John Dewey em suas investigações filosóficas. É importante ressaltar que, na época em que Dewey produziu sua obra - início do século 20 -, o método filosófico predominante confiava na autoridade da razão especulativa como instrumento na busca pelo conhecimento. Sem fazer referência a situações concretas, a mente investigava de maneira puramente conceitual a essência de ideias ou conceitos, a fim de descobrir sua causa ou finalidade absolutas e estabelecer, com base nisso, os fundamentos últimos da realidade. Tendo em vista esse horizonte, ao adotar um método que levasse em conta a experiência e a vida prática, a filosofia de Dewey teve de assumir a tarefa de redefinir muitas das noções tradicionais (ex.: democracia, educação, liberdade), com o intuito principal de despojá-las do prestígio distrativo da sua habitual condição de essência (de fim em si) e arrogarlhes a sua devida função de instrumento teórico (de meio) para fim de solucionar alguma situação concreta. Em razão disso, no caso da noção aqui estudada, em vez de procurar uma ideia geral de liberdade (como uma espécie fixa), o filósofo vai buscar na experiência as condições que caracterizam a liberdade enquanto conceito que indica algum problema concreto.

Segundo atesta Jerome Popp (2006), John Dewey foi o primeiro filósofo a manifestar a atitude denominada naturalismo evolutivo. Esta corrente filosófica se caracteriza pela visão de que o método científico é a principal forma de investigar a realidade, pela adoção da teoria darwiniana da evolução como fundamento principal em seus argumentos. Em sua obra Evolution's First Philosopher: John Dewey and the Continuity of Nature, comenta que

[...] enquanto outros filósofos podem ter dado alguma atenção à teoria evolucionária, foi Dewey sozinho quem viu que, se a mente emerge de formas prévias que não possuíam mente, então esse fato prognostica uma nova importância para o conhecimento, a ética e a democracia. (Popp, 2006, p.1).

Em um ensaio publicado em 1910, intitulado The Influence of Darwinism on Philosophy, John Dewey foi pioneiro na afirmação de que a concepção emergente das espécies promovida pela teoria evolutiva, 
ao atuar sobre a maneira como o conhecimento passou a ser buscado e apreciado pelas ciências orgânicas, tornou legítimo, por fim, o emprego do mesmo método no campo da filosofia. Cabe lembrar que, antes da publicação de A Origem das Espécies (1859) de Charles Darwin, a doutrina que concebia a natureza das coisas de forma perfeita e acabada vinha aos poucos sendo minada pela concepção de uma natureza que apenas gradualmente foi surgindo à existência.

O princípio da transição já havia sido provado ser mais eficaz e convincente que o método tradicional na área das ciências inorgânicas, como a astrologia, a física e a química (por exemplo, com as obras de Galileu, Descartes e Lavoisier); nas pesquisas referentes à vida orgânica, não obstante, ainda predominava a busca por alguma essência permanente e absoluta por trás da fluidez dos fenômenos, interditando, assim, ao novo método, a investigação da natureza humana e, por conseguinte, de temas como ética, política e liberdade.

Antes de Darwin, o impacto do novo método científico sobre a vida, mente, e política, foi impedido; porque entre esses interesses ideais ou morais e o mundo inorgânico, intervém o reino das plantas e animais. Os portões do jardim da vida estavam fechados às novas idéias; e apenas através desse jardim havia acesso à mente e política. A influência de Darwin na filosofia reside em ter conquistado o fenômeno da vida para o princípio da transição, e libertado assim a nova lógica para sua aplicação à mente, à moral e à vida. (Dewey, 1997, p.9-10).

Com John Dewey, é inaugurado um novo caminho para a investigação filosófica: o método genético fundamentado no naturalismo evolutivo. Também chamado pelo autor de método histórico ou evolucionário, ele consiste no "controle da análise ou interpretação de qualquer fenômeno ao trazer à luz as condições exatas, e apenas essas condições, que estão envolvidas no seu surgimento" (Dewey, 1902, p. 108-109). Segundo discorre em seu artigo The Evolutionary Method as Applied to Morality, publicado na revista The Philosophical Review em duas partes, em março e julho de 1902, o método genético, na investigação de fenômenos morais e valores éticos, possui eficiência semelhante ao método experimental que as ciências naturais utilizam na investigação de fenômenos físicos. ${ }^{3}$

Declara o autor no artigo:

\begin{abstract}
Meu objetivo é mostrar que o método histórico [ou genético] nos revela um processo em formação, e por isso traz sob controle intelectual e prático fatos que resistem terminantemente à especulação genérica ou à mera observação introspectiva. (Dewey, 1902, p. 113).
\end{abstract}

O objetivo desse método é, a exemplo do método científico, promover o controle do fenômeno em questão. De forma que, ao prever e controlar as condições do ambiente que promovem a manifestação do fenômeno, cresce no indivíduo o poder de domínio sobre ele, junto com a capacidade de reproduzi-lo, se desejável, ou evitá-lo, se pernicioso. Vê-se, pois, que o emprego do método genético na filosofia, ao empreender sua investigação acerca da liberdade, não perderá tempo procurando sua 
essência ou finalidade absoluta, mas perseguirá as condições físicas e sociais específicas que podem gerar a liberdade enquanto um fenômeno verificável. Encarada dessa maneira, a liberdade é percebida não como causa, mas como um efeito - um produto da evolução. Para John Dewey, a liberdade cresce. O livro Como Pensamos manifesta evidências de que é possível estudar as condições que promovem o seu crescimento a fim de encontrar maneiras, por meio da educação, de reproduzir essas condições.

O naturalismo evolutivo impele Dewey para longe das teorias que tratam a liberdade como atributo inato ou faculdade essencial do ser humano. Segundo Dewey, apenas a possibilidade da liberdade é inata no ser humano. Para que o seu desenvolvimento ocorra é necessário o concurso de condições específicas fornecidas pelo ambiente físico e social, em interação com as tendências instintivas do indivíduo. Sob essa perspectiva, o fenômeno que Dewey indica como sendo a manifestação da liberdade é a conduta reflexiva, isto é, a conduta humana baseada na ponderação, na busca de um objetivo claramente estipulado, na análise das circunstâncias, na formulação e verificação de hipóteses, na busca de meios para empreender seus intentos e na tentativa de superar os obstáculos que os estorvam. A liberdade nasce da formação de hábitos reflexivos. Como veremos, importa acentuar que, para promover as circunstâncias favoráveis ao exercício do pensamento reflexivo, é necessário, sobretudo, um esforço consciente por parte dos mais experientes na educação dos membros imaturos ${ }^{4}$ da sociedade. É sobre essas questões que trata a obra Como Pensamos.

\section{Liberdade e o pensamento reflexivo}

Segundo John Dewey, a verdadeira liberdade é intelectual. É a capacidade que tem um indivíduo de se orientar para um objetivo, levando em conta o uso dos meios adequados, de prever as consequências de seus atos, buscando obter os recursos materiais para realizá-los. Essa capacidade, que é justamente o diferencial humano entre as espécies vivas, denota antes um poder de controle: "Pois liberdade é poder de agir e executar independentemente de tutela exterior. Significa domínio, capaz de exercício independente, emancipado dos cordéis da direção alheia, não simplesmente atividade exterior sem peias" (Dewey, 1979, p. 93). Nesse sentido, o hábito de obedecer cegamente aos impulsos, cultivando a atividade espontânea e irrefletida, sem consideração pelas consequências dos seus atos, representaria justamente a conduta de um ser não livre. O curso espontâneo dos instintos observado no comportamento dos indivíduos imaturos não caracteriza uma conduta livre. Essa explosão impulsiva de potência que não encontra obstáculos representa, ao contrário, o grau zero de liberdade.

Ter o rumo das atividades dirigido pelas influências exteriores e pelos instintos é uma característica comportamental dos animais não humanos; todavia, não significa dizer que a liberdade, apesar de ser marca distintiva
${ }^{4}$ Dewey utiliza o termo "imaturo" para se referir aos indivíduos nesta fase de seu processo de crescimento. A imaturidade é constituída pela plasticidade comportamental, segundo o autor, e pela dependência em relação aos mais velhos. 
da espécie humana, seja um atributo inato. O ser humano nasce - como os demais animais - desprovido, ainda, da conduta caracterizada como reflexiva. E não há um ponto definido do seu desenvolvimento mental após o qual o indivíduo se torna livre de um momento para o outro; a liberdade vai apenas gradualmente sendo conquistada.

Adepto da teoria evolutiva, que advoga a mudança gradual e muitas vezes quase imperceptível da vida orgânica, John Dewey jamais admitiria uma iluminação repentina que libertasse o indivíduo do jugo de todas as influências, de modo que a partir desse momento ele se transformasse em um ser inteiramente racional e responsável. O desenvolvimento da liberdade deve ser observado desde a sua gênese em situações concretas, deve indicar a manifestação de algum fenômeno: esse fenômeno é o comportamento resultante do exercício do pensamento reflexivo. Pois a única liberdade possível e observável, segundo Dewey, é aquela que

[...] reside no poder do pensamento exercitado, na capacidade de 'virar as coisas pelo avesso', de examiná-las deliberadamente, de julgar se o volume e espécie de provas em mãos são suficientes para uma conclusão e, em caso negativo, no saber onde e como encontrar tais evidências. (Dewey, 1979, p. 96).

Em razão disso, a investigação empreendida por Dewey indaga que situação, ou que circunstâncias, estimulam o ser humano a pensar reflexivamente, promovendo nele o comportamento deliberado característico de um indivíduo considerado livre.

Existem, segundo Dewey, diferentes níveis de atividade mental. Pode-se dizer que grande parte do comportamento humano é conduzido por hábitos adquiridos irrefletidamente. Como ocorre com os outros animais, a acomodação (boa ou má) de nossos impulsos às condições do ambiente acaba criando padrões rotineiros de comportamento, mas, diferentemente deles, devido a aspectos evolutivos do nosso sistema nervoso, enquanto percebemos que nos tornamos mais conscientes, constatamos também que os hábitos mecânicos se estendem ao funcionamento mental, configurando uma expansão de atividades inconscientes. Em poucas palavras, isso quer dizer que nem toda inquietação da mente pode ser considerada um pensamento ou então, se for, não pode ser considerada pensamento reflexivo (Dewey, 1979).

Com base na consideração anterior, conclui-se que o mero ato de pensar do ser humano não configura necessariamente reflexão. Por essa perspectiva, concebemos que, inicialmente, a atividade mental tem todos os indícios para ser declarada inconsciente, ou irreflexiva, pois apresenta todas as características dos hábitos mecânicos do corpo. Paralelamente ao fluxo livre de ações espontâneas, comum a todos os animais, sobrevém no ser humano o fluxo de pensamentos. Trata-se de uma atividade mental determinada pelas circunstâncias, indicando exatamente aquela carência de liberdade que o ser humano, do alto do patamar evolutivo, costuma enxergar no animal irracional. Contudo, para Dewey, como o desenvolvimento científico e tecnológico representa prova concreta da 
existência do pensamento reflexivo, infere-se que, em algum momento, o comportamento do ser humano deixou de ser totalmente guiado pela conjunção de influências instintivas e ambientais e começou a ser estabelecido, paulatinamente, pelo próprio indivíduo.

Vejamos qual foi esse momento. No livro Democracia e Educação (publicado em 1916), o capítulo 3, intitulado A educação como direção, Dewey chama a atenção para o fato de o ser vivo não ser uma entidade passiva. O organismo se encontra, desde o início, sempre engajado em alguma operação. Em princípio, o estímulo externo dirige toda a atividade do ser vivo; fornece-lhe um objeto de desejo, um objetivo. A resposta do organismo representa a adaptação das suas tendências instintivas às influências do ambiente; "o estímulo é unicamente uma condição para o exercício conveniente das funções orgânicas" (Dewey, 1959, p. 26). Isso é mais facilmente verificável nos animais cuja ação visa apenas efetivar esquemas operativos inatos através de determinado estímulo fornecido pelo ambiente, para, em seguida, sendo consumada a vontade, se voltar para o próximo objeto que lhe guiará os passos. Da mesma forma, o ser humano mais novo terá as suas ações guiadas por estímulos físicos do ambiente que lhe chamem atenção, e sua inclinação permanecerá a de ocupar-se dessas coisas na medida em que vão surgindo em sua experiência até que, por meio da convivência com outros membros do grupo, seja aprimorada sua percepção de estímulos mais refinados, isto é, sociais (estes que, em seu tempo, exercerão forte influência sobre a conduta do ser humano maduro). De toda forma, nota-se que, em teoria, não parece haver espaço para uma direção autônoma; o indivíduo é regido por estímulos externos, sejam físicos ou sociais.

Entretanto, a experiência demonstra uma situação mais complexa. Na vida diária de qualquer organismo, apesar de certos estímulos dirigirem sua atividade até o fim, isto é, apesar de o indivíduo buscar sempre consumar seu desejo ou seu impulso, esse fluxo é constantemente bloqueado. Toda espécie de obstáculos impedem que o curso da ação atinja sua finalidade. Aqui é preciso considerar seriamente não apenas a frequência dessas obstruções, mas também a sua importância. Essa condição de interdição da atividade representa um problema, que, nas palavras do autor, "é tudo aquilo, por simples e trivial que seja, que põe o espírito em perplexidade, desafiando-o a tal ponto que a crença se faz incerteza" (Dewey, 1979, p. 22). Até aqui, devemos reconhecer que em toda atividade vital, por mais ínfima que seja, o indivíduo encontra obstáculos (problemas) no empenho em realizá-la, e devemos atentar para o fato de que, na espécie humana, esse pequeno fenômeno assume uma importância crucial.

O problema que impede a satisfação de um objetivo abre a possibilidade para o comportamento livre surgir e se desenvolver. A condição primária para o nascimento da reflexão ocorre quando o estímulo do ambiente não encontra nenhuma resposta no esquema de hábitos e costumes rotineiros do indivíduo, isto é, quando o ser humano vislumbra a perturbadora vastidão de possibilidades e a desconfortante sensação 
de não possuir a certeza de uma direção. Portanto, ali onde o ambiente obstrui o fluxo espontâneo e habitual e apresenta-lhe um problema a ser resolvido, surge no indivíduo a possibilidade do pensamento reflexivo. Como atesta o filósofo, "a imediata descarga direta ou expressão de uma tendência impulsiva é fatal ao ato de pensar. Somente quando o impulso é, em certo grau, tolhido e repelido sobre si mesmo, é que nasce a reflexão" (Dewey, 1979, p. 94). A reflexão entra onde o hábito mental rotineiro não dá mais conta das demandas do organismo; ela emerge de uma atividade entravada, de um impedimento. Ainda segundo o autor, a liberdade "é algo que se consegue através da vitória, pela reflexão pessoal, sobre as dificuldades que impedem uma ação imediata e um êxito espontâneo" (Dewey, 1979, p. 94). Quando resolve um problema ou supera um obstáculo, de modo a aprender com a experiência para prever e dominar situações semelhantes no futuro, cresce no indivíduo sua capacidade de controle e, por conseguinte, sua liberdade.

Contudo, para que se defina uma conduta como reflexiva, há que ser avaliada a maneira como o indivíduo responde à situação problemática. O reconhecimento de um problema, a estipulação de um objetivo, a projeção de possíveis soluções, estas etapas sozinhas ainda não caracterizam a reflexão. O traço distintivo desse tipo especial de pensamento é a busca por evidências, a verificação ou, em outros termos, o retorno à experiência - essa é a única espécie de pensamento que influi na realidade transformando e adaptando o ambiente em favor das intenções do indivíduo. Em razão disso, Dewey observa que somente o surgimento de um problema que obstrua a atividade do indivíduo, apesar de constituir uma condição fundamental para o exercício da reflexão, não garante obrigatoriamente a sua realização. Como consta na obra Como Pensamos, para impulsionar o uso do pensamento reflexivo, junto a um problema concreto da experiência como premissa maior, é necessário o concurso de outra influência.

[...] o pensar reflexivo, diferentemente das outras operações a que se dá o nome de pensamento, abrange: (1) um estado de dúvida, hesitação, perplexidade, dificuldade mental, o qual origina o ato de pensar; e (2) um ato de pesquisa, procura, inquirição, para encontrar material que resolva a dúvida, assente e esclareça a perplexidade. (Dewey, 1979, p. 22).

Este segundo fator de influência consiste, portanto, na adoção de uma postura crítica e inquisitiva por parte do indivíduo. Sabe-se que grande parte dos problemas cotidianos pode ser resolvida apenas seguindo as instruções de alguém que já os tenha resolvido antes, seguindo a tradição, por assim dizer, como uma espécie de fórmula de conduta. Contudo, se o indivíduo demonstra uma disposição investigativa, se sua busca por evidências o impele à pesquisa da origem e dos fundamentos, seja da tradição, seja de qualquer crença não verificada, sua compreensão do problema será maior, assim como a sua capacidade de lidar com situações análogas no futuro.

Do que foi dito até aqui, conclui-se que o surgimento de um problema na experiência juntamente com a adoção de uma postura inquisitiva 
reúnem as duas condições essenciais para promover o pensamento reflexivo. Dewey ensina como reproduzir essas condições. A primeira é mais fácil, pois não é preciso investir muito esforço na criação de problemas artificiais, uma vez que os seres humanos já têm de lidar com obstáculos que emergem naturalmente da sua experiência diária. Podemos aproveitar um punhado dessas adversidades reais e unir o útil ao agradável, ou seja, aproveitar o ensejo fornecido pela constatação de um problema concreto e investigar maneiras de resolvê-lo, exercitando, assim, o pensamento. Dewey caracteriza a segunda condição - a postura necessária - pelo conjunto de três atitudes fundamentais: 1) ter o espírito aberto, livre de preconceitos, disposto à consideração de novos problemas e novas ideias; 2) ter o interesse absorvido pela busca, possuir entusiasmo, paixão pela investigação da matéria, objeto, ou causa em questão; 3) ter responsabilidade, capacidade de prever e assumir as consequências dos seus atos e projetos (Dewey, 1979). Contudo, o autor adverte que tais atitudes não são naturais, tampouco se desenvolvem espontaneamente durante a vida do ser humano.

Em razão desse ponto, começamos a perceber que, para reunir os elementos que ocasionam a reflexão e que, por conseguinte, indicam a maneira pela qual o indivíduo pode ser mais livre, se faz necessário um projeto educacional com esse intuito. O cultivo de atitudes e o exercício do pensamento reflexivo não ocorrem espontaneamente, nem dependem do mérito exclusivo do indivíduo. Se o controle e a comunicação necessários à vida social não forem conduzidos de forma adequada, o indivíduo perde a possibilidade de compartilhar o conhecimento acumulado pelo grupo e absorver a experiência socializada. Em condições extremas, ele não teria sequer pleno domínio da linguagem (instrumento social sem o qual não se consegue pensar como um ser humano, em primeiro lugar). Logo, formar um ser independente, responsável - em suma, livre - não é possível sem um esforço deliberado por parte dos adultos na direção dos membros menos experientes. É necessária uma atuação educacional consciente. A perspectiva deweyana de uma sociedade formada por indivíduos inteligentes e autônomos se deve à fundamentação na teoria darwiniana da evolução, como será visto na seção seguinte. Convém, neste momento, somente confirmar a posição do filósofo em favor do cultivo do pensamento reflexivo como um fim educacional. Em poucas palavras, para Dewey, um dos objetivos principais da educação deveria ser dirigir a formação do indivíduo imaturo, com o intuito de capacitá-lo a assumir aos poucos a direção da sua formação.

\section{Liberdade como um fim educacional}

Não é supérfluo perguntar por que razão a liberdade, para John Dewey, deve ser um fim educacional. Como se pode deduzir do que foi dito até aqui, tal proposta não vem de uma apreciação estética e idealizada sobre o conceito de liberdade, tampouco da noção proveniente 
do liberalismo clássico, onde a liberdade é vista como um valor absoluto, um direito e uma condição inata do ser humano. Se Dewey advoga a importância do crescimento da liberdade no indivíduo, é somente por verificar seu valor por meio da interpretação do fenômeno à luz da teoria evolutiva. Dessa maneira, a liberdade, longe de ser um valor em si, só é tratada com importância pelo autor porque o seu naturalismo evolutivo o conduziu a essa conclusão; do contrário, é válido supor que o conceito de liberdade seria ignorado e outro mais adequado poderia ser adotado em seu lugar. Na verdade, pode-se dizer que isso já ocorre. Dewey prefere trabalhar com outras categorias e normalmente evita o termo liberdade. Sempre que dele se utilizou, foi com o intuito de se contrapor a outras filosofias da liberdade e de refrear a influência que estas exerciam sobre o pensamento do seu tempo. Essas considerações servem para acentuar que a ideia de liberdade, para Dewey, deve seu valor ao fato de ser um fim que parece concordar com a marcha evolutiva da espécie humana.

Esclarecido esse ponto, convém investigar como Dewey responde à questão de se a liberdade, escolhida como objetivo educacional, é um bom objetivo. Considerando que a sua filosofia adota o princípio da transição e da mudança contínua, deve ser a partir dos elementos transitórios da vida orgânica e social que o filósofo busca uma direção. Ele não levanta um ideal estático a ser perseguido, mas, como um cientista, busca algum fundamento firme, alguma constância verificada em meio às transformações, e essa constante vai ser justamente a própria mudança. Não o simples movimento, a mudança mecânica e aleatória das coisas inanimadas, mas um tipo específico de mudança que se verifica nos organismos vivos: o crescimento. Os seres vivos em geral, e os seres humanos em específico, apresentam uma marcha cumulativa que produz como resultado um aumento de complexidade orgânica e de adaptabilidade ao meio - eles crescem. Assim sendo, a questão que nos confronta é sobre a direção (ou educação) que devemos conferir a este crescimento dos seres humanos. Em um nível mais amplo, Jerome Popp ilustra bem o raciocínio que persegue a melhor direção que se pode dar à espécie:

\footnotetext{
Pense em termos de organismo lutando para sobreviver, isto é, sob a pressão da seleção natural. Além disso, imagine que o largo cérebro humano ainda está em evolução. Por meio de qual critério deveríamos julgar o crescimento da espécie desses organismos? Por meio de qual critério a natureza julga esse crescimento? O único critério existente para o crescimento desses organismos, seja em número ou em modificações genéticas, é a capacidade para mais crescimento. (Popp, 2006, p. 81).
}

Traduzindo em termos educacionais, segundo Dewey, isso quer dizer: "19) que o processo educativo não tem outro fim além de si mesmo: ele é seu próprio fim e que $2^{\circ}$ ) o processo educativo é um contínuo reorganizar, reconstruir, transformar" (Dewey, 1959, p. 53). Isso é o mesmo que afirmar que o crescimento do indivíduo não tem outro fim a não ser mais crescimento. Na medida em que os organismos foram se tornando mais complexos, surgiram formas superiores de inteligência. Se o cérebro 
humano permanece em evolução, isso é ainda hoje objeto de debate. Dewey, contudo, advoga que a inteligência humana certamente evolui. Eventualmente, essa inteligência criou a linguagem e a cultura, tornou-se consciente da própria existência, inventou métodos para modificar o ambiente em seu favor; enfim, começou a se tornar autônoma, ou seja, começou a ser livre. Promover a continuidade do desenvolvimento da inteligência humana, por meio do cultivo consciente do pensamento reflexivo, foi o meio que Dewey encontrou para contribuir com o crescimento da espécie.

Para justificar sua tese, no início do segundo capítulo do livro Como Pensamos, nomeado "Por que o ato de pensar reflexivo deve constituir um fim educacional", Dewey procura definir, em linhas gerais, os valores do pensamento reflexivo. O autor separa três efeitos da reflexão que evidenciam a importância do seu cultivo para o contínuo crescimento da inteligência do ser humano. Cabe examiná-los. Em primeiro lugar, o filósofo diz que o ato de pensar reflexivo possibilita a ação consciente, pois torna o indivíduo capaz de dirigir e projetar suas atividades com previsão e de acordo com propósitos deliberados. "Trazendo à mente as consequências de diferentes modalidades e linhas de ação, o pensamento [reflexivo] faz-nos saber "a quantas andamos ao agir. Converte uma ação puramente apetitiva, cega e impulsiva, em ação inteligente" (Dewey, 1979, p. 26). Pelo pensamento reflexivo, o indivíduo é capaz de planejar objetivos futuros e obter domínio sobre circunstâncias que ainda não se encontram presentes.

Em segundo lugar, a reflexão possibilita a invenção sistemática e o engenho de técnicas úteis à vida humana. Ao observar com atenção a civilização contemporânea, pode-se verificar por toda parte, monumentos, dispositivos artificiais, mecanismos que foram modificando ao longo do tempo as condições antes primitivas da vida humana, promovendo um ambiente remodelado, com o intuito de fazer lembrar, ou prevenir, os membros do grupo de certas emergências da vida. Sobre isso, segundo declara John Dewey:

Todas as espécies de aparelhos artificiais são modificações intencionais de coisas naturais, de tal modo engendradas que as coisas nos passam a servir melhor do que sem seu estado natural, para revelar-nos o que estiver oculto, ausente e remoto. (Dewey, 1979, p. 28).

Dessa forma, é aguçada no indivíduo a percepção de estímulos complexos, refinados por meio da cumulação de técnicas e conhecimentos ao longo de gerações.

Por último, o pensamento reflexivo enriquece os objetos com um significado. A reflexão altera o sentido e, por isso, o valor da experiência. "Talvez não tenhamos a necessidade de pensar perante uma ocorrência; se, todavia, tal ocorrência já foi objeto de cogitação, o resultado desta capitaliza-se como sentido diretamente enriquecido e aprofundado." (Dewey, 1979, p. 30). Por fim, para concluir a justificativa da importância do pensamento exercitado, tanto sobre desenvolvimento da inteligência 
humana e, por conseguinte, da civilização, quanto, por essas mesmas razões, como fim educacional da espécie, Dewey comenta que

[...] os três valores mencionados, em seu efeito cumulativo, marcam a diferença entre uma vida verdadeiramente humana e racional e a existência vivida pelos animais que ficam presos numa rede de sensações e apetites. Os valores descritos, entretanto, não se realizam automaticamente, senão dentro de estreito limite, reforçado pelas necessidades da vida. Para obter que se realize adequadamente, cumpre que o pensamento receba orientação educacional cuidadosa e atenta. (Dewey, 1979, p. 31).

Dewey confirma que o desenvolvimento da inteligência humana depende da educação. Certamente, no livro Como Pensamos, o autor visa instruir os educadores, tutores e pais, nas maneiras de desenvolver o pensamento reflexivo nos seus alunos, discípulos e filhos. Todavia, o que o filósofo realmente tem em mente é instruir a espécie humana, fornecer-lhe uma direção que leve em conta as evidências científicas e evolutivas. Para Dewey, a partir de Darwin, a própria compreensão do processo pelo qual viemos a existir, imediatamente, torna a evolução nossa responsabilidade.

A compreensão de Popp vai na mesma direção quando comenta:

Se a inteligência que a natureza colocou em movimento se desenvolveu ao ponto de estar mudando o curso do processo que controlou nosso planeta antes da sua existência, então nosso problema se torna aquele de manejar essa inteligência. Em outras palavras, nossa inteligência não está mais sob controle da natureza. Nós tomamos a evolução em nossas próprias mãos e, junto com isso, a responsabilidade pela prosperidade do planeta. (Popp, 2006, p. 86-87).

Então, quando Dewey fomenta uma educação que vise ao crescimento constante da inteligência dos seres humanos, ele está se dirigindo à espécie, ou, quando menos, a alguma sociedade que tenha como ideal o crescimento contínuo da liberdade de todos os seus membros. Isso porque a educação, enquanto função social, depende inteiramente dos valores e ideais que determinado grupo social deseja perpetuar e dos indivíduos que esse grupo pretende formar. É evidente que os valores e os ideais variam de uma sociedade para a outra, e, apesar de certamente acreditar que a direção fornecida por sua filosofia da educação sirva para guiar a espécie inteira, Dewey não está interessado em impor sua visão a todas as sociedades. Ele procura, por meio do argumento, convencer de que a melhor maneira de alcançar esse objetivo seria promover um ambiente social no qual o número de interesses compartilhados pelos cidadãos fosse cada vez maior e no qual as relações com outras associações fossem cada vez mais intensas e livres. Dewey denomina democrática a sociedade que mais se aproximar de satisfazer esses critérios.

É importante advertir que o uso do termo democracia torna a obra de Dewey propícia a interpretações divergentes. Um dos seus maiores comentadores no Brasil, Marcus Vinicius da Cunha (2001), em seu livro John Dewey: A utopia democrática, entende que a democracia, para 
Dewey, é um imperativo moral, isto é, que a busca pela democracia é uma finalidade primordial, fundamentada não por teorias sobre a natureza humana, mas por uma espécie de fé utópica do filósofo norte-americano. Cunha assevera que "do ponto de vista deweyano, não devemos e não precisamos justificar a democracia com teorias sobre a natureza humana" (Cunha, 2001, p. 49); para o educador brasileiro, a legitimidade da utopia democrática de Dewey não está em sua base naturalista, mas na própria esperança de que a utopia venha a se concretizar.

Não é negado no presente estudo o caráter relativamente utópico da democracia deweyana, se por utopia entendermos um projeto visando a um futuro melhor, nem mesmo a evidente esperança do filósofo nesse sentido. Mas é um equívoco restringir-se apenas a esse aspecto utópico e, acima de tudo, declarar que a fundamentação da democracia é baseada puramente na fé de Dewey, ou dos seres humanos em geral, em sua concretização. Talvez a origem desta interpretação se deva ao fato de Cunha se basear principalmente na obra Liberalismo, Liberdade e Cultura ${ }^{5}$ para analisar a visão democrática de Dewey, deixando em segundo plano o que o filósofo norte-americano diz sobre o assunto nos já citados trabalhos de 1902 e 1910 e no livro Democracia e Educação. Neste último, Dewey parte das premissas mais básicas do naturalismo evolutivo e aos poucos vai montando suas ideias e propostas, chegando, assim, ao conceito de democracia. A aparente ausência da obra Democracia e Educação nesta interpretação de Cunha acaba se revelando problemática, como podemos perceber na passagem a seguir:

Segundo Dewey, a democracia só faz sentido como imperativo moral, jamais como imperativo psicológico ou filosófico. A democracia é algo que desejamos que aconteça, independentemente das inclinações naturais humanas, sejam elas quais forem, independente da Verdade Última, seja ela qual for, porque julgamos que a vida democrática propicia o melhor para a experiência atual e futura de humanidade, por ser o único modo de vida que permite crescimento individual e coletivo. (Cunha, 2001, p. 52).

Curiosamente, apesar de defender que a concepção de democracia de Dewey não é fundamentada na natureza humana, na sentença grifada, Cunha acaba deixando escapar a base naturalista em que ela, de fato, se apoia.

Ao contrário do excerto acima, a posição assumida neste artigo é de que Dewey leva sim em conta as inclinações naturais humanas e que, por isso mesmo, assume como "verdade última" essa própria natureza (por intermédio do princípio do crescimento), o que resulta numa concepção de democracia que, longe de ser uma finalidade, é apenas um meio: sua justificativa é ser exatamente o "único modo de vida que permite crescimento individual e coletivo" (Cunha, 2001, p. 53). Tem sido mais de uma vez sustentado aqui que o fundamento principal da filosofia deweyana é o principio da continuidade e do crescimento da vida baseado no conhecimento científico sobre a evolução e que todo o resto dos argumentos de sua obra se assenta consonantemente nessa base.
5 Combinação das obras Liberalism and Social Action (1935) e Freedom and Culture (1939), ambas traduzidas por Anísio Teixeira e publicadas no Brasil em 1970. 
As apropriações da filosofia de Dewey que ignoram esse ponto tendem geralmente a errar o alvo. Seguindo esse raciocínio, Jerome Popp afirma que

o desenvolvimento da nossa inteligência está subordinado apenas a ele mesmo, no sentido de que o crescimento como fundamento requer que as reconstruções da nossa experiência ocorram sempre de modo a promover o maior crescimento possível. Assim, democracia está subordinada ao crescimento, o que significa que o valor da democracia é secundário. (Popp, 2006, p. 85).

Cunha acaba trocando os fins pelos meios quando assevera que a educação é "uma poderosa ferramenta a serviço da democracia" (2001, p. 53), quando, na verdade, é a democracia a ferramenta a serviço do crescimento da liberdade. Do que foi dito, conclui-se que foi a observância do critério do crescimento que induziu Dewey a estipular como fim educacional a formação de indivíduos cada vez mais livres e independentes; conclui-se também que essa escolha se deveu à compreensão do processo evolutivo. É, pois, dessa posição que decorre a concepção de democracia que o filósofo defende. Dewey chama de comunidade democrática aquele grupo social que tem como fim educacional promover maior inteligência e maior liberdade.

\section{A pedagogia da liberdade segundo John Dewey}

Esclarecida a noção de liberdade e a razão por que ela deve ser cultivada, resta agora estabelecer sua diferença com relação à outra concepção de liberdade preponderante nas discussões sobre a educação. Contrapondo-se à noção deweyana, está a concepção de liberdade que se identifica à: 1) ausência de direção exterior; 2) crítica à educação reprodutivista; ${ }^{6}$ 3) recusa da autoridade. Para caracterizar essa corrente, será utilizada a expressão "pedagogia não diretiva", ou "não diretivismo", que remeterá a esse sentido estrito, especificamente de acordo com as quatro características mencionadas. Dewey afirma em sua obra Experiência e Educação (publicada em 1938) que:

Não é demais dizer que uma filosofia educacional que declare ter como base a ideia de liberdade possa se tornar mais dogmática do que a educação tradicional contra a qual, no entanto, procura reagir. Qualquer teoria, bem como qualquer conjunto de práticas, pode tornarse dogmática se não tomar como base o exame crítico de seus próprios princípios fundamentais. (Dewey, 2010, p. 24).

${ }^{6}$ É a posição que critica a ideia de educação como função social que promove simplesmente a preservação e perpetuação da sociedade. Condena-se principalmente o seu papel de transmissão de conhecimentos e reprodução dos valores e interesses específicos do grupo social em que a educação ocorre.

Seu alvo é justamente esta atitude pedagógica que, em nome de um ideal não refletido de liberdade, recusa-se a dirigir e controlar a experiência do imaturo no percurso educativo. Apesar da crítica de Dewey ter sido feita explicitamente àquela filosofia da educação que surgia em sua época, como reação a educação tradicional, a apropriação dessa crítica no presente estudo estende consideravelmente a lista de teorias 
que se encaixam nesses critérios. Se for bem analisado, esse conjunto de vertentes teóricas reúne, hoje em dia, não apenas a didática baseada na Aprendizagem Centrada no Aluno de Carl Rogers e seus continuadores, mas a influência em bloco das teorias pós-modernas na pedagogia, compreendendo os estudos culturais, e suas ramificações de gênero (por ex.: a teoria Queer), de etnia (com os estudos pós-colonialistas), e os demais trabalhos sobre educação baseados nas teorias pós-estruturalistas (ou na sua versão americana nominada desconstrucionismo). ${ }^{7}$

Quanto à primeira característica da noção de liberdade da pedagogia não diretiva, a ausência de direção exterior, é de supor que na seção Liberdade e pensamento reflexivo tenha ficado claro que o comportamento da criança é dirigido exteriormente, quer queira ela ou não - queiram os educadores ou não. É particularmente perigoso que a influência dos movimentos que lutam contra a direção exterior atinja a prática pedagógica. Isso é dito devido à evidente incapacidade que apresenta um infante para tomar decisões que lhe sejam benéficas. Suponhamos que aceitemos à risca a incumbência de não dirigir a atividade da criança. Antes de tudo, deve-se saber que sua ação ainda estará sendo dirigida, só que por estímulos indiscriminados do ambiente que motivam impulsos cegos e irrefletidos, como ocorre nos animais considerados irracionais. "Em termos morais, a pessoa madura, em certas ocasiões, não tem o direito de sonegar aos mais jovens a capacidade de compreensão compatível com o que a sua experiência proporcionou" (Dewey, 2010, p. 39). Para algum lugar a criança está indo. Além disso, por possuir tendências mais complexas que outros organismos mais simples, o ser humano é o animal que mais depende do cuidado dos membros mais velhos enquanto ainda é imaturo.

A direção exterior permanece existindo nas práticas não-diretivas, com a diferença de que nestas a direção é mal conduzida; pois, por ser tida como inexistente, não se conhece direito sua função e, por conseguinte, não se servem dela de maneira eficiente os educadores. O professor que renuncia à direção da conduta da criança usa da própria autoridade para fazê-lo. Conclui-se, dessa forma, que toda pedagogia é diretiva. A questão é: como proceder diante desse fato? A solução proposta por John Dewey é utilizar a autoridade para dirigir as atividades da criança, a fim de consolidar no indivíduo as condições necessárias para que um dia ele não precise mais de orientação, para que ele consiga desenvolver a habilidade da reflexão consequente e, assim, alcance a independência e a autonomia tão apreciada pelo não diretivismo. Em poucas palavras, a criança depende de um adulto que tenha boa vontade, conhecimento e experiência suficientes para indicar o caminho que formará nela um juízo crítico e independente.

O segundo aspecto dessa ideia de liberdade é a defesa de que a sociedade não deveria impor seus valores e crenças aos mais novos, que eles devem ser livres para escolher seus próprios valores e crenças. É importante, nesse momento, ressaltar que para a visão naturalista de John Dewey, a educação, em seu sentido mais lato, é o instrumento fundamental da continuidade social da vida. No livro Democracia e Educação, educação

\footnotetext{
${ }^{7}$ Uma das principais vias de acesso do pensamento pósestruturalista no Brasil se deu através do estudo sobre currículo da obra Documentos de Identidade (1999), de Tomaz Tadeu da Silva.
} 
é uma função necessária a toda comunidade que almeje preservar sua vida característica, pelo menos por mais de uma geração. Não só a educação formal (ou escolar), mas, sobretudo, a informal (aquela que ocorre por meio das atividades compartilhadas no meio social) exerce um papel essencial na formação da conduta dos membros mais novos do grupo. Por isso ela muda de acordo com os valores assumidos por cada sociedade. É notório que os indivíduos humanos, quando imaturos, necessitam de proteção e cuidado dos mais velhos. O simples cultivo físico, isto é, o simples trabalho de manter sua subsistência, não os prepara para participar das atividades desenvolvidas pelos membros mais experientes do grupo. É necessário um esforço consciente com o intuito de prepará-los para substituir os mais velhos na execução de trabalhos complexos característicos da sua sociedade. Da mesma forma, aos indivíduos mais novos são transmitidos valores, crenças e ideais do grupo (Dewey, 1959).

Antecipando acusações de reprodutivismo, vale esclarecer que o que foi descrito no parágrafo anterior não representa um conceito deontológico ou normativo; não indica o que a educação deve ser. Indica, antes, a função da educação em todo grupo social. Tratou-se do fato verificável de que os adultos dirigem as atividades dos imaturos de acordo com seus interesses, e que o fazem de forma tanto intencional quanto involuntária, quer admitam ou não esse papel. A reprodução dos ideais e valores dos mais velhos aos mais novos é um fato social incontestável. Como já foi sugerido, Dewey assevera que a única maneira de uma sociedade superar a prática educativa da mera reprodução é adotar como valor e ideal a ser reproduzido o próprio crescimento, isto é, a própria renovação da sociedade. Dessa forma, o que se reproduz é a disposição e a mentalidade voltada a formar indivíduos cada vez mais inteligentes, que contribuam para a reconstrução e transformação do grupo.

Percebe-se, assim, que as duas primeiras características da pedagogia não diretiva são fundadas na recusa de dois fatores biológicos básicos: a direção externa - o fato de toda forma de vida depender dos estímulos do ambiente para satisfazer seus instintos e realizar suas atividades - e a reprodução - o fato de a renovação da vida se dar por meio da transmissão de informações (seja no nível molecular ou social). Essa teoria se recusa a reconhecer tais fatos primários com base em algum ideal de liberdade que postula a não intervenção ou mesmo a abstenção da responsabilidade que têm os mais experientes na direção das crianças. Ela nunca poderia ser efetivamente aplicada - a prática educativa nas escolas claramente mantém ainda métodos diretivos -, mas, o que é mais problemático, para ajustar a realidade aos seus ideais, vem produzindo um discurso pedagógico que pode ser considerado escorregadio, quase exclusivamente hermenêutico e carregado de eufemismos. A valorização da interpretação subjetiva da realidade, incentivada por essa teoria, tem como efeito principal, na academia, as múltiplas narrativas individuais elevadas à condição de documentos científicos fidedignos. Nas escolas, se por um lado vem contribuindo para uma gradual mudança no valor da cultura e individualidade do aluno, por outro resulta muitas vezes na recusa da 
autoridade do professor. E este é o terceiro aspecto dessa corrente a ser aqui considerado.

A noção de liberdade carregada pelo não diretivismo representa em sua essência o rompimento das amarras. É um movimento radical de libertação. Nesse processo, a religião, os pais, o professor, toda autoridade é rejeitada. Dewey considera que

a rejeição à filosofia e à prática da educação tradicional apresenta um novo tipo de difícil problema educacional para os que acreditam em um novo tipo de educação. Enquanto não reconhecermos esse fato e enquanto não aceitarmos definitivamente que não é abandonando o velho que resolveremos qualquer problema, continuaremos atuando de maneira cega e confusa. (Dewey, 2010, p. 26).

A escola tradicional passa a ser comparada a um regime ditatorial. Na verdade, o impulso que adquire a forma de negação da direção, representa a negação, não apenas do autoritarismo extremo, mas de toda forma de autoridade. Diria Dewey que, como ocorre constantemente na história, a posição revolucionária julga desprezível toda cultura tradicional, sem fazer distinção do que nela é nocivo ou que pode ser útil, e "o impulso consequente é - como em toda reação - passar ao extremo oposto" (Dewey, 1979, p. 89). As correntes pedagógicas não diretivas representam, portanto, uma reação ao autoritarismo, mas incorrem no erro de não reconhecer a existência e a importância da autoridade nas relações educativas.

A ausência de toda autoridade, na criança, não resulta na liberdade, mas na atividade impulsiva e imprevidente, o que configura uma experiência não educativa. A criança não aprende a usar a experiência para prever e controlar situações semelhantes no futuro. A atitude diretiva tipicamente naturalista a ser tomada aqui é conhecer o fato e trabalhar com base nele.

Já que o propósito a ser realizado deve vir, direta ou indiretamente, de algum ponto do ambiente, negar-se ao professor o poder de propô-lo é simplesmente substituir, pelo contato acidental com outras pessoas ou cenas, o planejamento inteligente da única pessoa que, se algum direito tem de ser professor, melhor conhece as necessidades e possibilidades dos componentes do grupo do qual é parte. (Dewey, 1979, p. 270).

Em poucas palavras, se for realmente necessária uma autoridade, que seja uma autoridade competente; se necessária uma direção, que seja uma direção que vise ao amplo desenvolvimento da liberdade do ser humano. Que as reais condições da relação educativa sejam reconhecidas para que o projeto pedagógico seja factível, de base sólida e confiante, selecionando os conteúdos em vista da formação proposta.

\section{Considerações finais}

Foi afirmado acima que a noção deweyana de liberdade tem como uma das suas funções principais contrapor-se ao ideal de liberdade das 
teorias pedagógicas não diretivas, demonstrando a inaplicabilidade destas e os perigos que sua pretensão à cientificidade pode causar. Também foi argumentado que, se a liberdade cresce, e se seu crescimento é determinado por condições da interação entre o indivíduo e o ambiente, é porque ela está sujeita aos mesmos princípios e regularidades que a investigação científica descobre operando no mundo natural. A liberdade, então, não sendo oposta ao processo natural, é na verdade um efeito desse processo, na medida em que a natureza inclui o ser humano e a própria sociedade.

Assim como sabe que a inteligência humana surgiu da combinação casual e cumulativa de diversos fatores, sem obedecer a nenhuma razão deliberadamente projetada - como é explicado pela teoria da evolução -, Dewey reconhece que as instituições e a organização social não surgiram de um planejamento racional, mas de uma combinação similarmente casual e cumulativa de fatores, como o desenvolvimento do comércio e das indústrias, como as viagens e migrações, como as lutas e conquistas. Todavia, ao advogar que, uma vez tendo a humanidade o domínio científico das forças naturais e a compreensão das suas condições reais de existência, a responsabilidade da direção da espécie humana deixa de ser arbitrária e irrefletida e passa a ter a possibilidade de ser autônoma (de governar a si própria), John Dewey pode ser considerado um defensor da liberdade. Pois ele destaca a espécie humana da marcha parcialmente aleatória e cega da mera luta pela sobrevivência e a eleva a uma condição capaz de assumir a direção racional e deliberada dessa mesma marcha.

Conclui-se, dessa forma, que, se a evolução das formas orgânicas da natureza deu ensejo ao aparecimento da inteligência, não mais cabe meramente às injunções da natureza o crescimento da espécie. A partir desse momento, cabe à inteligência se utilizar das condições naturais para promover o seu crescimento, acelerando o processo que antes era arrogado somente à autoridade irrefletida da natureza. Sob essa perspectiva, a educação se mostra uma função social de fundamental importância para por em prática o processo de formação de indivíduos reflexivos, independentes, livres.

\section{Referências bibliográficas}

CUNHA, Marcos Vinicius. John Dewey: a utopia democrática. Rio de Janeiro: DP\&A, 2001.

DEWEY, John. Como pensamos: como se relaciona o pensamento reflexivo com o processo educativo: uma reexposição. São Paulo: Companhia Editora Nacional, 1979.

DEWEY, John. Democracia e educação: introdução à filosofia da educação. São Paulo: Companhia Editora Nacional, 1959. 
DEWEY, John. Experiência e educação. Petrópolis: Vozes, 2010.

DEWEY, John. Liberalismo, liberdade e cultura. São Paulo: Companhia

Editora Nacional : Ed. USP, 1970.

DEWEY, John. The evolutionary method as applied to morality. The Philosophical Review, v. 11, p. 107-124, 353-371, mar./july 1902.

Disponível em: < http://www.jstor.org/stable/2176631>. Acesso em: 12 abr. 2013.

DEWEY, John. The influence of Darwinism on philosophy. In: DEWEY, John. The influence of Darwin on philosophy and other essays. New York: Prometheus Books, 1997.

POPP, Jerome A. Evolution's first philosopher: John Dewey and the continuity of nature. New York: State University of New York, 2007.

SILVA, Tomaz Tadeu. Documentos de identidade: uma introdução às teorias do currículo. Belo Horizonte: Autêntica, 1999.

Rômulo Ferreira Correa, acadêmico do curso de Pedagogia da Universidade do Estado de Santa Catarina (Udesc), Florianópolis, Santa Catarina, Brasil. É bolsista de iniciação científica do projeto "Dewey e Dennett: as concepções de comunicação e de mente no contexto da filosofia da educação".

romulo_correa@hotmail.com

José Claudio Matos, doutor em Filosofia pela Universidade de São Paulo (USP), é professor do Centro de Ciências Humanas e da Educação da Udesc, Florianópolis, Santa Catarina, Brasil.

doutortodd@hotmail.com

Recebido em 16 de julho de 2013.

Aprovado em 10 de dezembro de 2013. 